\title{
O CLIMA URBANO DA CIDADE DE OURINHOS/SP: DIAGNÓSTICO DAS VARIÁVEIS METEOROLÓGICAS
}

\author{
Ana Claudia Bento ${ }^{(a)}$, Sabrina Laís Basso ${ }^{(b)}$, Jonas Teixeira Nery ${ }^{(c)}$ \\ (a) Instituto de Ciência e Tecnologia, UNESP Sorocaba, anacbento@outlook.com \\ (b) Instituto de Ciência e Tecnologia, UNESP Sorocaba, bassolais@ gmail.com \\ (c) Departamento/Faculdade, UNESP/Ourinhos, Email - jonas@ ourinhos.unesp.br
}

\section{Eixo: CLIMATOLOGIA EM DIFERENTES NÍVEIS ESCALARES: MUDANÇAS E VARIABILIDADES}

\begin{abstract}
Resumo
O objetivo desse trabalho está no entendimento das variáveis climáticas do município de Ourinhos, pois o modelo urbano adotado pela cidade pode ser bom para seu crescimento e desenvolvimento, porém pode ser ineficaz na questão climatológica, já que a falta de planejamento urbano, o uso e ocupação e a retirada da vegetação natural do município é propicia a uma série de problemas para população como o desconforto térmico, problemas de saúde, calamidades, tais como inundações, destruição do solo e poluição atmosférica. O estudo do conforto térmico no município de Ourinhos é justificável diante da necessidade de identificar a relação das variáveis meteorológicas com o meio urbano, bem como suas possíveis consequências na qualidade de vida desta população.
\end{abstract}

Palavras chave: Ourinhos; Clima Urbano; variáveis meteorologicas;

\section{Introdução}

A finalidade deste estudo é analisar o clima de Ourinhos-SP através das variáveis meteorológicas, para se entender como ocorre o quadro de desconforto térmico na cidade e qual sua relação com o clima do município e avaliar a temperatura, precipitação pluvial e umidade relativa do ar, pois o modelo urbano adotado pela cidade pode ser bom para seu crescimento e desenvolvimento, porém pode ser ineficaz na questão climatológica, já que a falta de planejamento urbano, o uso e ocupação e a retirada da vegetação natural do município é propícia a uma série de problemas para população como o desconforto térmico, problemas de saúde, calamidades, tais como inundações, destruição do solo e poluição atmosférica. Com isso o estudo do conforto térmico no município de Ourinhos é justificável diante da necessidade de identificar a relação das variáveis meteorológicas com o meio urbano, bem como suas possíveis consequências na qualidade de vida desta população.

Os dados obtidos são retirados de dez postos de coletas por estações automáticas e aparelhos espalhados dentro do município, para conseguir caracterizar a cidade como um todo. 


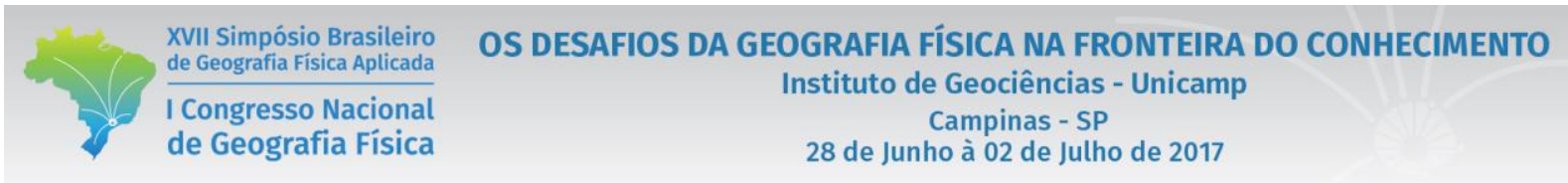

\subsection{Caracterização da área da análise do trabalho}

Este trabalho apresenta como área de estudo o município de Ourinhos que possui uma área de 296 km² (IBGE 2008), localiza-se no sudoeste do estado de São Paulo, divisa com o norte do estado do Paraná (Figura 1). A cidade possui uma área urbana de $40 \mathrm{~km}^{2}$, uma área rural de 256 $\mathrm{km}^{2}$ totalizando uma área de $296 \mathrm{~km}^{2}$, Possui uma população de 109.228 habitantes (IBGE 2005), com uma densidade demográfica de $367,45 \mathrm{hab} / \mathrm{km}^{2}$. Segundo o IBGE possui um grau de urbanização de 96,3 \%. Possui também uma área de matas e florestas de 398 hectares e uma área de pastagens naturais de 1.703 hectares (IBGE 2006). Sua topografia é levemente acidentada, o que não gera grandes barreiras de ventos. Localiza-se próximo ao trópico de Capricórnio e apresenta um clima tropical úmido (classificação de Köppen, conforme pode ser observado na Figura 1, caracterizada por inverno seco, aonde o mês mais frio tem temperatura média maior que $\left.18,0^{\circ} \mathrm{C}\right) .(\mathrm{CNPF}, 2011)$.

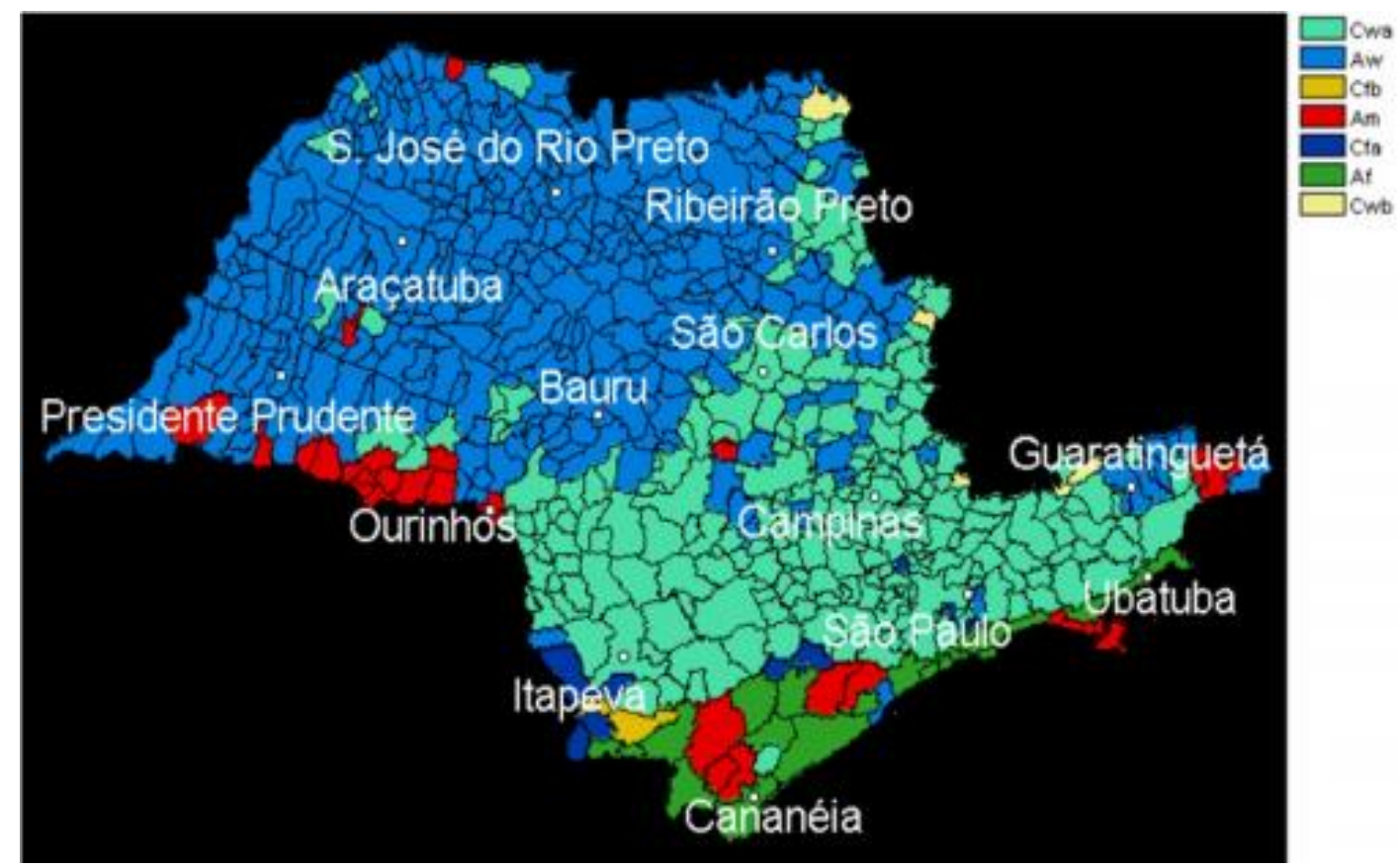

Figura 1: Classificação Climática de Köppen do Estado de São Paulo.

Fonte: Centro de pesquisas Meteorológicas e Climáticas aplicadas á Agricultura (CEPAGRI, 2011). 


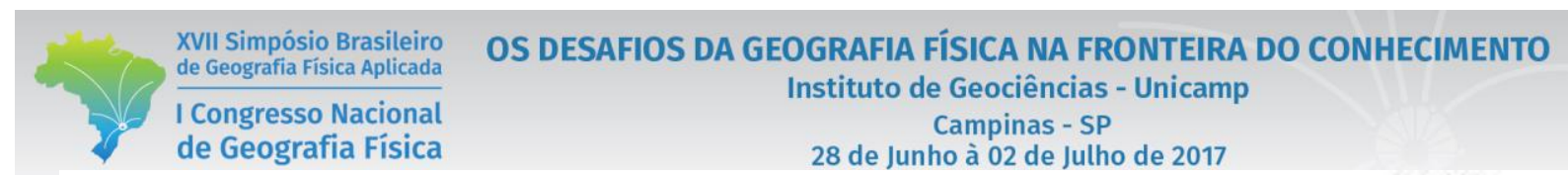
de Geografia Física $\quad 28$ de Junho à 02 de Julho de 2017
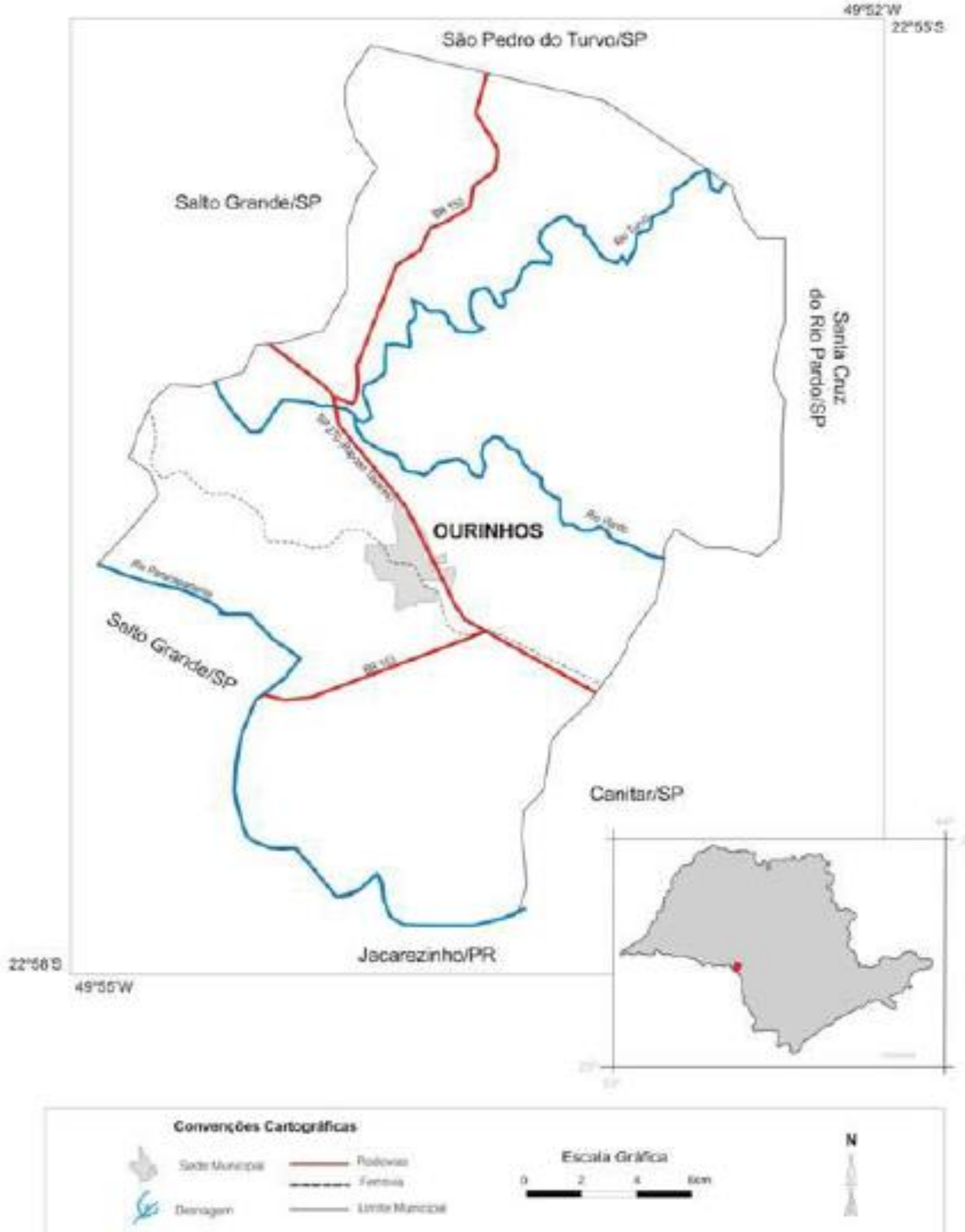

Figura 2: Mapa de localização do município de Ourinhos/SP no sudoeste do estado de São Paulo. Fonte: Zacharias (2006). 


\section{OS DESAFIOS DA GEOGRAFIA FÍSICA NA FRONTEIRA DO CONHECIMENTO \\ Instituto de Geociências - Unicamp \\ Campinas - SP \\ 28 de Junho à 02 de Julho de 2017}

\section{Procedimentos metodológicos}

Primeiramente foram realizados os levantamentos dos dados de precipitação pluvial, obtidos junto a Agência Nacional de Águas (ANA), no site HIDROWEB, dos nove pontos instalados na cidade pela UNESP Ourinhos (Figura 2), além do Instituto Agronômico de Campinas (IAC) que também possui uma base de dados meteorológicos, além da instalação de mais dois pontos, para contemplar a análise do município como um todo, mostrando todos os pontos de coletas dentro e fora da área urbana do município (Figura 3).

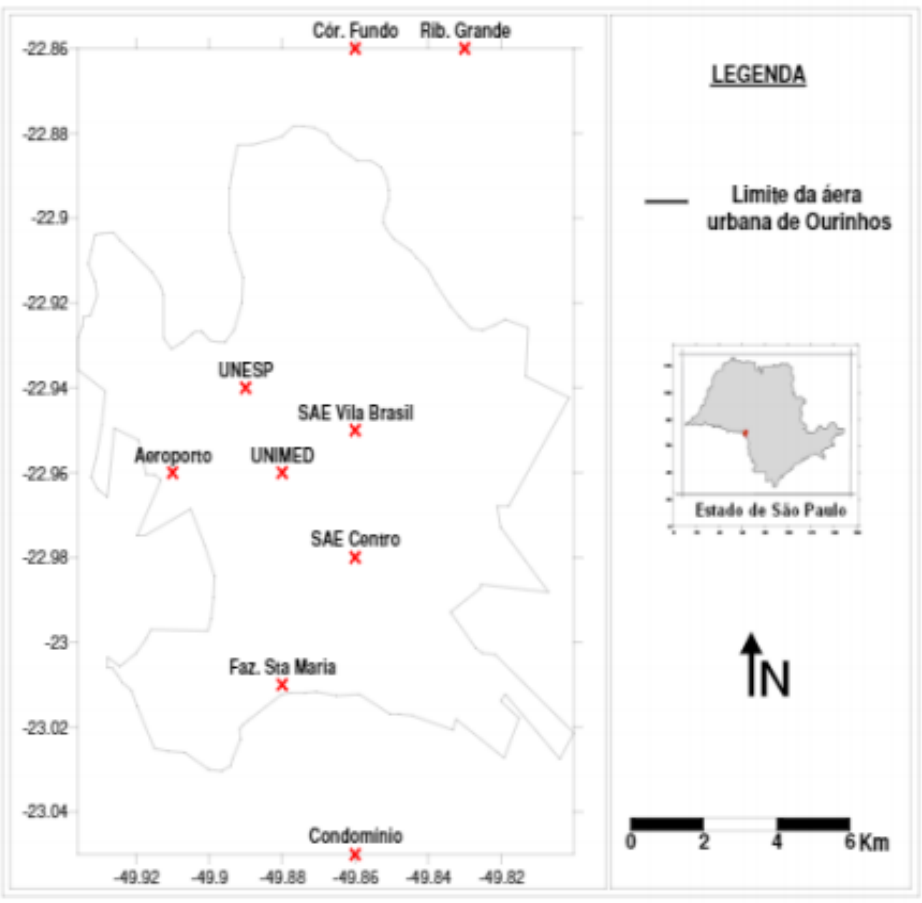

Figura 3: Pontos de coletas das nove estações meteorológicas de Ourinhos.

Foram realizados cálculos e trabalhos de campos mensalmente para as construções de gráficos de balanço hídrico, climograma, distribuição temporal da média e desvio padrão mensal das estações pluviométricas para uma caracterização do município, que foram todos sendo organizados utilizando o ambiente da planilha do software Microsoft Office Excel. Essa planilha também tratou os dados para classificação das anomalias de anos secos e chuvosos.

Todos os dados obtidos em campo foram tabulados e trabalhados em planilhas do Excel, onde foi possível a construção de gráficos e parâmetros estatísticos que facilitaram a melhor visualização 


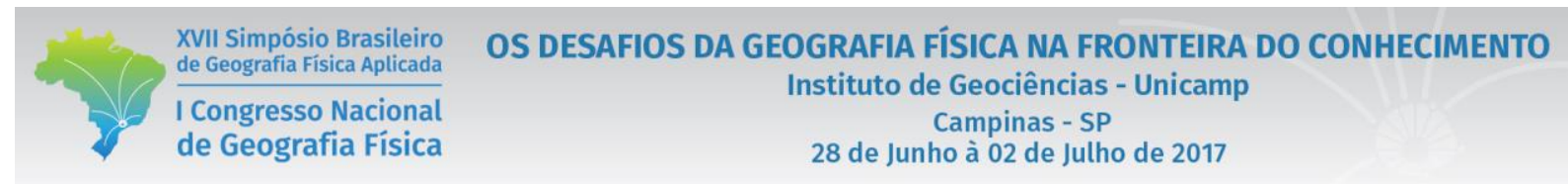

dos resultados, para assim com os resultados obtidos nas planilhas fossem espacializados no software Surfer, utilizando o método de interpolação de Krige, gerando mapas de isolinhas para distribuição dos resultados e gráficos de comparação no Word;

\section{Resultados e discussões}

Para os pontos de coleta se trabalha com duas metodologias: a de áreas externas e a de áreas internas, já quanto à precipitação pluvial, foram se analisados dados junto a Agência Nacional de Águas (ANA), além do Instituto Agronômico de Campinas (IAC) que também possui uma base de dados meteorológicos. A pesquisa é feita por base de dados brutos colhidos mensalmente em campo que são suficientes para a análise climatológica, para uma melhor visualização dos resultados e os resultados obtidos são gerados mapas de isolinhas das variáveis para análise de conforto térmico, facilitando assim a visualização de possíveis campos de ilhas de calor ou frescor e de umidades, como mostra a figura 4. Durante todo o período de coleta foi consultado os documentos de Meteorologia Sinótica, para proporcionar um melhor entendimento sobre as dinâmicas climáticas em Ourinhos. Todos os resultados obtidos estão sendo classificados pelo modelo usado pelo laboratório MASTER (IAG/USP) por considerar o modelo mais adequado para as latitudes tropicais.
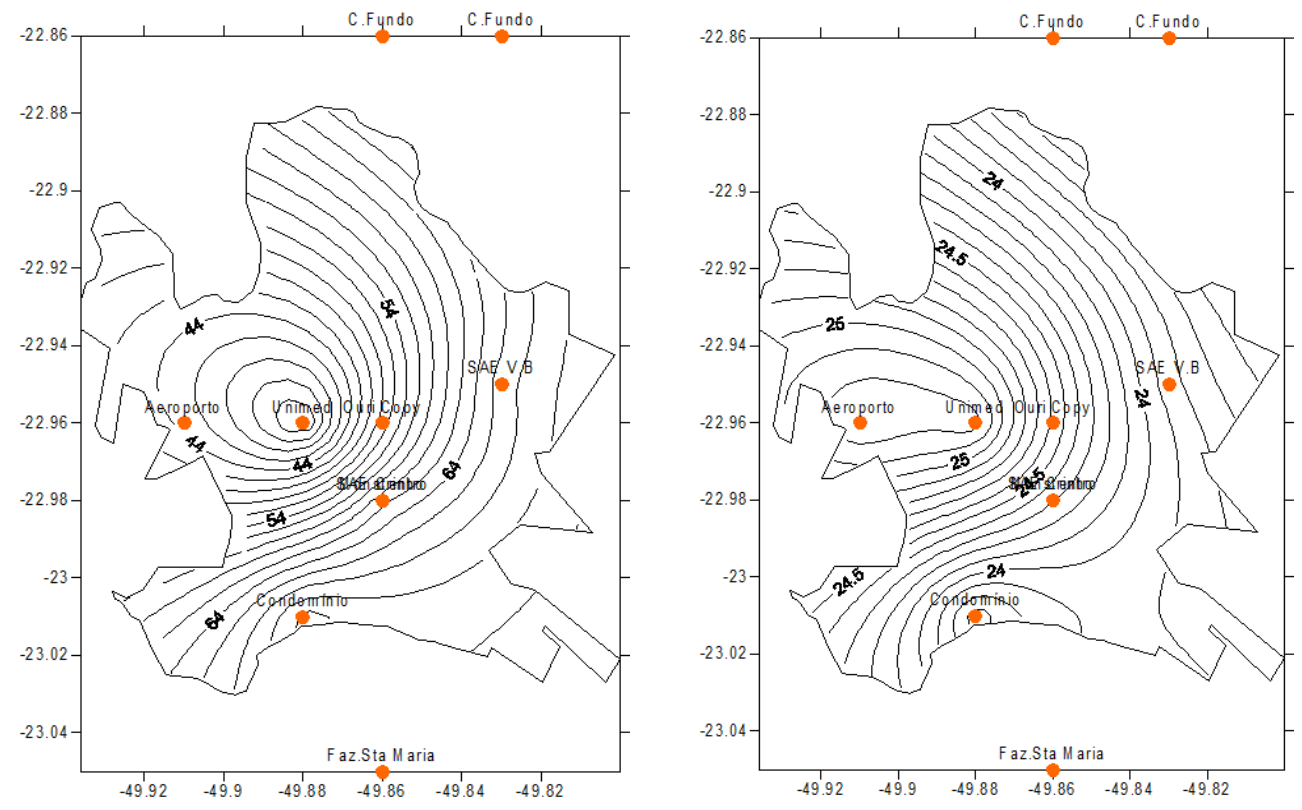

Figura 4: Resultados de umidade relativa e temperatura ás 8h do dia 06 de fevereiro de 2014. 


\section{Considerações Finais}

Conclui-se que a homogeneização dos dados, mostra-se eficiente e capaz de assegurar dados mais realísticos dentro do município e observa-se que as variáveis meteorológicas mostram bem a realidade do microclima que é significativa. Tendo em vista essa análise climatológica, a compreensão das características desses dados na cidade de Ourinhos, apresenta-se como uma ferramenta indispensável para o conhecimento acerca da distribuição espacial da umidade relativa, temperatura, índice de conforto/desconforto térmico e velocidade do vento, onde será possível a partir disso tentar minimizar as altas temperaturas que as cidades apresentam, conferindo a possibilidade de se obter grandes contribuições em pesquisas sobre os impactos provocados pela urbanização e sua influência sobre a vida humana.

\section{Bibliografia}

AMORIM, M. C. C.T. O clima urbano de Presidente Prudente/SP. São Paulo, 2000. 378p. Tese (Doutorado em Geografia) - Faculdade de Filosofia Letras e Ciência Humanas - USP.

AYOADE, J. O. Introdução à climatologia para os trópicos. São Paulo: Difel, 1986.

INSTITUTO BRASILEIRO DE GEOGRAFIA E ESTATÍSTICA. Cidades: Ourinhos. Disponível em: 2006. Acesso em: fevereiro 2013 IBGE. Censo Demográfico 2010. Disponível em: Acesso em: fevereiro 2013.

KÖPPEN, W. 1948. Climatologia. Ed. Fondo de Cultura Económica, México.

MENDONÇA, F. O Estudo do Clima Urbano no Brasil: Evolução, tendências e desafios. In:

MONTEIRO C. A. de F. Teoria e Clima Urbano. São Paulo: IGEOG/USP, 1976. 181p. (Série Teses e Monografias, 25).

MONTEIRO, C. A. F. Teoria e Clima Urbano: Um projeto e seus caminhos. In: MONTEIRO, C. A. F. \& MENDONÇA. F. (Org.) Clima Urbano. São Paulo: Editora Contexto, 2003.

SANT'ANNA NETO, J. L. Os Climas das cidades brasileiras. org.- Presidente Prudente: [s.n] 2002. 